\title{
Erratum
}

Tyler B. Coplen* and Yesha Shrestha

\section{Erratum to: Isotope-abundance variations and atomic weights of selected elements: 2016 (IUPAC Technical Report)}

https://doi.org/10.1515/pac-2018-0504

Erratum to: Tyler B. Coplen and Yesha Shrestha. 2016. Isotope-abundance variations and atomic weights of selected elements: 2016 (IUPAC Technical Report). Pure and Applied Chemistry. Volume 88, Issue 12, pages 1203-1224. (DOI:10.1515/pac-2016-0302):

The following errors appeared in the Technical Report [1] published in Pure and Applied Chemistry in 2017:

p. 1210: The lower bound of the $10^{3} \delta^{30} \mathrm{Si}_{\mathrm{NBS28}}$ value of "Quartz sandstones" in Fig. 8 should be -7.5 instead of -5.7 .

p. 1217: The value in column 2 of Table 8 for "Quartz sandstones" should be -7.5 instead of -0.2 .

p. 1217: The value in column 4 of Table 8 for "Biogenic silica" should be +6.1 instead of +2.5 .

p. 1217: The reference in the last column for "Biogenic silica" is incorrect and should be Ding et al. [2].

p. 1217: The value in column 2 of Table 9 for "Atmospheric $\mathrm{H}_{2} \mathrm{~S}$ ” should be -32 instead of -21 .

The U.S. Geological Survey Data Release [3], which contains an Excel file listing the atomic weight and isotopic abundances for each isotope of each of the twelve elements for each substance and material shown in Fig. 1-12 and Tables 1-12, has been updated [3]. In the Technical Report this data release is identified as “[232]." These data may also be found on the web site of IUPAC’s Commission on Isotopic Abundances and Atomic Weights [4].

\section{References}

[1] T. B. Coplen, Y. Shrestha. Pure Appl. Chem. 88, 1203 (2017). https://doi.org/10.1515/pac-2016-0302.

[2] T. P. Ding, G. R. Ma, M. X. Shui, D. F. Wan, R. H. Li. Chem. Geol. 218, 41 (2005). https://doi.org/10.1016/j.chemgeo.2005.01.018.

[3] T. B. Coplen, Y. Shrestha. Tables and Charts for Isotope-Abundance Variations and Atomic Weights of Selected Elements: 2016 (Ver. 1.1, May 2018): U.S. Geological Survey Data Release, (2018). https://doi.org/10.5066/F7GF0RN2.

[4] Commission on Isotopic Abundances and Atomic Weights, http://ciaaw.org/natural-variations.htm.

*Corresponding author: Tyler B. Coplen, U.S. Geological Survey, Reston, VA, USA, e-mail: tbcoplen@usgs.gov. https://orcid.org/0000-0003-4884-6008

Yesha Shrestha: U.S. Geological Survey, Reston, VA, USA. https://orcid.org/0000-0002-9714-8516 